\title{
Medications for Anxiety: A Drug utilization study in Psychiatry Inpatients from a Tertiary Care Centre of Western Nepal
}

\author{
Banerjee I1 ${ }^{1}$, Roy B2 , Sathian B ${ }^{3}$, Banerjee I4, Kumar SS 5 , Saha A6
}

${ }^{1}$ Lecturer, Department of Pharmacology, Manipal College of Medical Sciences, Pokhara, Nepal

${ }^{2}$ Assistant Professor, Department of Physiology, Manipal College of Medical Sciences, Pokhara, Nepal

${ }^{3}$ Assistant Professor, Department of Community Medicine, Manipal College of Medical Sciences, Pokhara,

Nepal

${ }^{4}$ Junior Resident, MS General surgery, Kolkata Medical college, West Bengal, India

${ }^{5}$ Lecturer, Department of Physiology, Manipal College of Medical Sciences, Pokhara

${ }^{6}$ Professor \& HOD, Department of Pharmacology, Manipal College of Medical Sciences, Pokhara, Nepal

\section{Original Article}

\section{Corresponding Author}

Dr. Indrajit Banerjee MD

Lecturer, Department of Pharmacology,

Manipal College of Medical Sciences,Pokhara,Nepal

E-mail: indrajit18@gmail.com

\section{Abstract}

\section{Background}

Anxiety is the most widespread psychiatric disorder and generalized anxiety disorder is the most common disease seen in the primary care setting. Currently there are a number of anxiolytic drugs commercially available in the market for treatment of these disorders such as Benzodiazepines like Diazepam, Chlordiazepoxide, Alprazolam, Betablockers like Propranolol and $\mathrm{H} 1$ Antihistaminics like Hydroxyzine. Some of the newer anxiolytics like Buspirone in Azapirone group is marketed as better anxiolytic drug than the traditional drugs. Buspirone is promoted as a better drug for anxiety, as it does not cause any sedation, tolerance or physical dependence. A need for study further increases as there is no sufficient data on utilization pattern of anxiolytics on Nepalese population. This is the first study done in the utilization pattern of anxiolytic drugs in inpatient in Nepal.

\section{Methods}

This is an observational study undertaken between $1^{\text {st }}$ October 2009 and $31^{\text {st }}$ March 2010 at the Psychiatric inpatient Department of Manipal Teaching Hospital. The prescribing pattern of Anxiolytic drugs was measured. Out of a total of 240 cases who were admitted to psychiatry inpatient ward, 38 cases have received Anxiolytic drugs. Those who were critically ill with anxiety were included in the study.

\section{Results}

Out of 240 cases who were admitted to psychiatry inpatient, 130 were male patients $(54.2 \%), 95 \% \mathrm{Cl}$ $[47.9,60.5]$ and the rest were female patients $(45.8 \%), \mathrm{Cl}$ $[39.5,52.1]$. In 38 cases of anxiety, the age of the patient $<40$ years $89.5 \%$ and $>40$ years $10.5 \%$. Anxiety was more common in females $71.1 \%$ than in males $28.9 \%$. $68.4 \%$ of the patients were unemployed whereas only $31.6 \%$ of the patients were employed. $78.9 \%$ of the drugs were prescribed by trade name. Among the anxiolytics, the commonest drug prescribed was Alprazolam (50\%), followed by Clonazepam (31.6\%), Chlordiazepoxide (15.8\%) and Lorazepam (2.6\%).

\section{Conclusion}

Utilization patterns of drugs for anxiolytics were according 
to treatment guidelines and suggested a trend towards the use of shorter acting Benzodiazepines such as Alprazolam. Continuous and prolonged use of longer acting Benzodiazepines has resulted in dependence and may have withdrawal symptoms when the dosage of these drugs is reduced or treatment is stopped.

Keywords: Anxiolytics, Psychiatry, Drug utilization study, Inpatients

\section{Background}

Drug utilization study is one of the fundamental watchtowers of promoting rational use of medicine for treatment of various diseases, surveying the field of healthcare and leading to a greater understanding of the development that underlies it ${ }^{1}$. Anxiety is the most widespread psychiatric disorder and generalized anxiety disorder is the most common disease seen in the primary care setting ${ }^{2,3}$. Anxiety is an unpleasant sensation characterized by apprehension, tension and fear of unknown which can develop in a normal person e.g. before an exam. Anxiety can be classified as two types, namely general anxiety (when anxiety is persistent) and episodic anxiety like phobia and panic disorder. In Panic disorder, a patient remains in a state of anxiety without any adequate cause, lasting for few minutes, characterized by palpitation, fear of unknown, sweating, dyspnea, etc. Phobia is an abnormal fear, triggered by a single stimulus, set of stimuli, which are predictable and normally cause no particular concern to others. Phobia is classified into following types like agoraphobia, claustrophobia, social phobia, simple phobia etc.

According to a literature survey done in August 2008 by Jonathan R. T et al for the period 1987-2009, anxiolytic drug groups benzodiazepines, azapirones, antihistamines, antidepressants, alpha-2-delta ligands, antipsychotics, and named drugs buspirone, venlafaxine, duloxetine, fluoxetine, escitalopram, olanzapine, paroxetine, pregabalin, quetiapine and risperidone, in addition to psychological therapies and cognitive-behavioral therapy, are commonly used treatment modalities ${ }^{4}$.

According to a six month prevalence rate reported in a World Health Organization (WHO) study in 14 countries including US, about $8 \%$ of patients come to a primary care with generalized anxiety disorder ${ }^{5}$. According to the European Study of the prevalence of Mental Disorders prevalence of anxiety is only $2.8 \%{ }^{6}$.

Most of the studies that have been undertaken in Nepal are about the prevalence of mental illness. Only one study has been undertaken in 2001 in outpatient department of Psychiatry in Western Nepal, in which it was shown that $71.3 \%$ of the drugs were prescribed by the brand names. The frequency of use of antidepressants were $45.94 \%$, anxiolytics $19.41 \%$, antipsychotics $8.6 \%$ and antimanics $1.96 \%^{7}$.

Currently there are a number of anxiolytic drugs commercially available in the market for treatment of mental disorders including Benzodiazepines like Diazepam, Chlordiazepoxide, Alprazolam, Betablockers like Propranolol andH1 Antihistaminics like Hydroxyzine. Some of the newer anxiolytics like Buspirone in Azapirone group is marketed as better anxiolytic drug than the traditional drugs. Buspirone is promoted as a better drug for anxiety, as it does not cause any sedation, does not produce any tolerance or physical dependence.

This is the first study done in the utilization pattern of anxiolytic drugs in inpatients in Nepal. By carrying out this study, one is expected to get an idea regarding clinician's choice and patient's tolerability of anxiolytic drugs. There is no sufficient data on utilization pattern of anxiolytics on Nepalese population, such studies are increasingly relevant. The main objective of the study is to find the commonest anxiolytic drug prescribed in a tertiary care centre with severe form of anxiety in hospitalized patients.

\section{Material and Methods}

\section{Study design and the participants}

A Prospective observational cross sectional study was done at Manipal Teaching Hospital, Pokhara, Nepal. It was chosen for the study because Manipal teaching hospital is a tertiary care hospital in Western Nepal and it was expected that all the critically ill psychiatric cases with anxiety will report to this hospital from Western Nepal.

\section{Data collection}

The present study was undertaken between $1^{\text {st }}$ October 2009 and $31^{\text {st }}$ March 2010, at Manipal Teaching hospital, Psychiatric inpatient department, at the bed side after interviewing with them. The prescribing pattern of anxiolytic drugs was measured. The data was analyzed with respect to specific factors, using following indication: Classification based on (ATC) Anatomical Therapeutic Chemical Classification, using the data on prescription, General parameters like Age ( $<40$ years and $>40$ years), Sex (male and female), Occupation (Housewife, teacher, labourer, shopkeeper, student, farmer, retired and others), Religion (Hindu, Christian, Muslim), Ethnicity (Brahmin, Chettri, newar, dalit and others), Employment (employed and unemployed), Monthly Income (<10000/month and $>10000 /$ month, Treatment (Drug monotherapy and drug and psychotherapy, Based on essential drug list (esential or non essential), Trade/Generic, Commonest drug were used. In types of treatment anxiolytic dugs and combination of drugs (Anxiolytics with fluoxetine) were used.

The Anatomical Therapeutic Chemical (ATC Code) ${ }^{9}$

\begin{tabular}{|c|c|}
\hline Generic Name & ATC Code \\
\hline Chlordiazepoxide & N05BA02 \\
\hline Lorazepam & N05BA06 \\
\hline Alprazolam & NO5BA12 \\
\hline Clonazepam & NO3AE01 \\
\hline Fluoxetine & NO6ABO3 \\
\hline
\end{tabular}




\section{Inclusion criteria}

All the patients admitted in psychiatric inpatient department with anxiety from October 2009 to March 2010 were included in the study. 38 cases had received Anxiolytic drugs and those who were seriously ill with anxiety were included in the study.

\section{Exclusion criteria}

Out of 240 cases who were admitted in the Psychiatry inpatients only 202 cases were excluded from the study because we wanted to find the drug utilization pattern of Anxiolytics drugs only. Other cases of Schizophrenia, Depression, Mania, Bipolar disorder, Substance abuse, suicidal tendencies and mental retardation were excluded from the study. All the out patients were also excluded from the study as we wanted to find the drug utilization study in those patients who are critically ill with anxiety for which hospitalization is required.

\section{Sample size calculation}

For $95 \%$ confidence interval and, significance level $\alpha=5 \%, P$ $=90 \%, Q=10 \%$, allowable error $=11 \%$, required sample size was 35. $\quad \mathrm{P}=$ percentage of Anxiolytics drugs used for the treatment of anxiety ${ }^{8}$.

\section{Outcome Variables}

Outcome variables were Treatment (Drug monotherapy, drug and psychotherapy), types of treatment (Anxiolytics, combined therapy), and essential drug list of Nepal (essential and nonessential drugs).

\section{Explanatory variables}

The demographic and psychiatric disorders were defined at individual level. Factors at individual level were Age $(<40$ years and $>40$ years), gender (male and female), monthly income $<10000 /$ month and $>10000 /$ month), employment of the patient (employed and unemployed).

\section{Ethical committee approval}

Preceding the study, ethical committee approval was taken from the ethical committee.

\section{Data management and statistical analysis}

Descriptive statistics and testing of hypothesis were used for the analysis. The data collected was analyzed using Excel 2003, R 2.8.0 Statistical Package for the Social Sciences (SPSS) for Windows Version 16.0 (SPSS Inc; Chicago, IL, USA) and EPI Info 3.5.1 Windows Version. The $Z$ test was used to examine the difference between different variables and strength of the relationship with logistic regression. We calculated odds ratios (OR) and their 95\% confidence intervals $(95 \% \mathrm{Cl}) . \mathrm{p}<0.05$ is considered as statistically significant.

\section{Results}

\section{Socio-Demographic Details}

Our study showed that 130 inpatients were male (54.2\%), $95 \% \mathrm{Cl}[47.9,60.5]$ and the rest were female patients
$(45.8 \%), 95 \% \mathrm{Cl}[39.5,52.1]$. In case of 38 cases of anxiety, $89.5 \%$ of the patients were less than 40 years of age and $10.5 \%$ were older than 40 years. Anxiety was more common in females $71.1 \%$ than in males $28.9 \% .86 .8 \%$ of the patients had a monthly income of less than Nepali Rupees 10000/per month and $13.2 \%$ earned more than 10000/- per month. $68.4 \%$ of the patients were unemployed whereas only $31.6 \%$ of the patients were employed with anxiety. 97.4\% of the patients were Hindus and Christians were only 2.6\%. According to the ethnicity $36.8 \%$ were Brahmin and Chettri $31.6 \%$ followed by Dalit $23.7 \%$, Newar $5.3 \%$ and others $2.6 \%$. $39.5 \%$ of the cases were housewives followed by students $21.1 \%$ and then teachers $15.8 \%$.

Table 1: Cross tabulation between psychiatric disorders in inpatients and Gender of the patients

\begin{tabular}{|c|c|c|c|c|}
\hline $\begin{array}{l}\text { Psychiatric } \\
\text { disorders }\end{array}$ & Male & Female & Total & P Value \\
\hline Schizophrenia & $\begin{array}{l}57(65.5) \\
{[55.5,75.5]}\end{array}$ & $\begin{array}{l}30(34.5) \\
{[24.5,44.5]}\end{array}$ & $\begin{array}{l}87(36.3) \\
{[30.2,42.3]}\end{array}$ & $0.0001+$ \\
\hline Depression & $\begin{array}{l}17(44.7) \\
{[28.9,60.5]}\end{array}$ & $\begin{array}{l}21(55.3) \\
{[39.5,71.1]}\end{array}$ & $\begin{array}{l}38(15.8) \\
{[11.2,20.5]}\end{array}$ & $0.356 x$ \\
\hline Mania & $\begin{array}{l}5(55.6) \\
{[23.1,88.0]}\end{array}$ & $\begin{array}{l}4(44.4) \\
{[12.0,76.9]}\end{array}$ & $\begin{array}{l}9(3.8) \\
{[1.3,6.2]}\end{array}$ & $0.635 x$ \\
\hline Bipolar & $\begin{array}{l}11(55.0) \\
{[33.2,76.8]}\end{array}$ & $\begin{array}{l}9(45.0) \\
{[23.2,66.8]}\end{array}$ & $\begin{array}{l}20(8.3) \\
{[4.8,11.8]}\end{array}$ & $0.525 x$ \\
\hline Anxiety & $\begin{array}{l}11(28.9) \\
{[14.5,43.4]}\end{array}$ & $\begin{array}{l}27(71.1) \\
{[56.6,85.5]}\end{array}$ & $\begin{array}{l}38(15.8) \\
{[11.2,20.5]}\end{array}$ & $0.0001+$ \\
\hline Others & $\begin{array}{l}29(60.4) \\
{[46.6,74.3]}\end{array}$ & $\begin{array}{l}19(39.6) \\
{[25.7,53.4]}\end{array}$ & $\begin{array}{l}48(20.0) \\
{[14.9,25.1]}\end{array}$ & $0.037^{*}$ \\
\hline Total & $\begin{array}{l}130(54.2) \\
{[47.9,60.5]}\end{array}$ & $\begin{array}{l}110(45.8) \\
{[39.5,52.1]}\end{array}$ & 240 & $0.067 x$ \\
\hline
\end{tabular}

$\dagger p<0.01$, statistically significant

$* p<0.05$, statistically significant

$\times p>0.05$, statistically not significant

\section{Psychiatric disorders}

Table 1 shows that out of 240 cases admitted to the psychiatry ward, the most common psychiatric disorder was Schizophrenia $36.3 \%$ and other diseases like substance abuse, behavioral disturbances, mental retardation and suicidal tendencies constituted $20 \%$, followed by Depression and anxiety disorders $15.8 \%$. Mania $3.8 \%$ and Bipolar disorders $8.3 \%$ were the least in number. There were $65.5 \%$ male and $34.5 \%$ female patients, $95 \% \mathrm{Cl}$ [55.5, 75.5 and 24.5, 44.5 respectively] suffering from Schizophrenia, which was found to be highly statistically significant $(P=0.0001)$. In Depression, out of 38 cases, male and female patients were $44.7 \%$ and $55.3 \%$ respectively, $95 \% \mathrm{Cl}[28.9,60.5$ and $39.5,71.1]$. In case of Mania, in 9 cases male and female patients were $55.6 \%$ and $45.4 \%$ respectively, $95 \% \mathrm{Cl}$ [23.1, 88.0 and 12.0, 76.9]. In case of Bipolar disorders out of 20 cases, male and female patients were $55 \%$ and $45 \%$ respectively $95 \% \mathrm{Cl}[33.2,76.8$ and $23.2,66.8]$. In patients with anxiety out of 38 cases, the percentage of male and female patients were $28.9 \%$ and $71.1 \%$, 95\% Cl [14.5,43.4 and $56.6,85.5$ ] which was found to be highly statistically significant $(P=0.0001)$. In case of other psychiatric cases, 
male and female patients were $60.4 \%$ and $39.6 \%$ respectively and $95 \% \mathrm{Cl}[46.6,74.3$ and $25.7,53.4]$.

Figure 1 depicts that as per as occupation of the patient is concerned housewives (39.5\%) $95 \% \mathrm{Cl}[23.9,55.0]$, suffer more from anxiety which is followed by students $(21.1 \%)$ 95\% Cl [8.1,34.0], and teachers(15.8\%) $95 \% \mathrm{Cl}$ [4.2,27.4], laborer (5.3\%) 95\% Cl[0.12.4],farmer (5.3\%)95\% Cl [0,12.4], retired (2.6\%) 95\% $\mathrm{Cl}[0,7.7]$, shopkeeper (2.6\%) $95 \%$ $\mathrm{Cl}[0,7.7]$ and others $(7.9 \%)(95 \% \mathrm{Cl}[0,6.5]$.

Figure 1: Occupations of patients suffering from anxiety

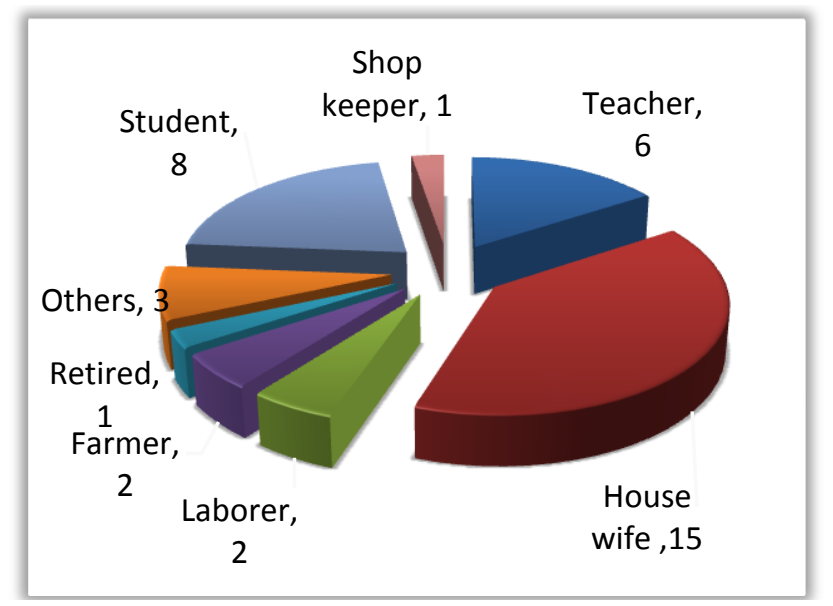

Table2: Cross tabulation between Socio demographic factors and Treatment, and Types of treatment

\begin{tabular}{|c|c|c|c|c|c|}
\hline \multirow{2}{*}{\multicolumn{2}{|c|}{$\begin{array}{l}\text { Socio demographic } \\
\text { factors }\end{array}$}} & \multicolumn{2}{|l|}{ Treatment } & \multicolumn{2}{|c|}{ Types of treatment } \\
\hline & & \multirow{2}{*}{$\begin{array}{l}\text { Drug } \\
\text { Monotherapy } \\
17 \text { (89.5) }\end{array}$} & $\begin{array}{l}\text { Drug and } \\
\text { Psychotherapy }\end{array}$ & Anxiolytics & \multirow{2}{*}{\begin{tabular}{|l} 
Combined \\
$6(85.7)$
\end{tabular}} \\
\hline \multirow{4}{*}{ Age } & $<40$ yrs & & $17(89.5)$ & $28(90.3)$ & \\
\hline & $>40$ yrs & $2(10.5)$ & $2(10.5)$ & $3(9.7)$ & 1 (14.3) \\
\hline & Total & $19(100)$ & $19(100)$ & $31(100)$ & $7(100)$ \\
\hline & P Value & $0.0001+$ & $0.0001+$ & $0.0001+$ & $0.0001+$ \\
\hline \multirow{4}{*}{ Gender } & Male & $4(21.1)$ & $7(36.8)$ & $7(22.6)$ & $4(57.1)$ \\
\hline & Female & $15(78.9)$ & $12(63.2)$ & $24(77.4)$ & $3(42.9)$ \\
\hline & Total & $19(100)$ & $19(100)$ & $31(100)$ & $7(100)$ \\
\hline & P Value & $0.0001 \dagger$ & $0.09^{x}$ & $0.0001+$ & $0.589^{x}$ \\
\hline \multirow{4}{*}{ Employment } & Employed & $5(26.3)$ & $7(36.8)$ & $8(25.8)$ & $4(57.1)$ \\
\hline & $\begin{array}{l}\text { Un } \\
\text { employed }\end{array}$ & $14(73.7)$ & $12(63.2)$ & $23(74.2)$ & $3(42.9)$ \\
\hline & Total & 19(100) & $19(100)$ & $31(100)$ & $7(100)$ \\
\hline & P Value & $0.0001+$ & $0.0001+$ & $0.0001+$ & $0.08^{x}$ \\
\hline \multirow[t]{4}{*}{$\begin{array}{l}\text { Monthly } \\
\text { Income }\end{array}$} & $\begin{array}{l}<10000 \\
\text { /month }\end{array}$ & $17(89.5)$ & $16(84.2)$ & $28(90.3)$ & $5(71.4)$ \\
\hline & $\begin{array}{l}>10000 \\
\text { /month }\end{array}$ & $2(10.5)$ & $3(15.8)$ & $3(9.7)$ & $2(28.6)$ \\
\hline & Total & 19(100) & $19(100)$ & $31(100)$ & $7(100)$ \\
\hline & P Value & $0.0001+$ & $0.09^{x}$ & $0.0001+$ & $0.589^{x}$ \\
\hline
\end{tabular}

$+p<0.01$, statistically significant

$* p<0.05$, statistically significant

$\times p>0.05$, statistically not significant
Table 2 reveals cross tabulation between Sociodemographic factors and treatment and type of treatment. If the age of the patient is $<40$ years, patients receiving drug monotherapy $89.5 \%$, drug and psychotherapy $89.5 \%$, Anxiolytics $90.3 \%$, Combined therapy $85.7 \%$ was found to be highly statistically significant $(P=0.0001)$. $78.9 \%$ female patient received drug monotherapy and $77.4 \%$ of female patient received Anxiolytics which was found to be highly statistically significant $(P=0.0001)$. If the patient is unemployed $73.7 \%$ patient received drug monotherapy, $63.2 \%$ received drug and psychotherapy, $74.2 \%$ received Anxiolytics $(P=0.0001)$. If the monthly income is $<10000$, $89.5 \%$ received drug monotherapy only and $90.3 \%$ received Anxiolytics ( $P=0.0001)$.

Table 3: Logistic regression table of Essential drug list and socio demographic factors

\begin{tabular}{|c|c|c|c|c|}
\hline \multicolumn{2}{|c|}{ Socio demographic factors } & \multicolumn{2}{|c|}{ Essential Drug List } & \multirow{2}{*}{$\begin{array}{l}\text { Odds ratio and } \\
\text { Confidence interval }\end{array}$} \\
\hline & & $\begin{array}{l}\text { Non } \\
\text { essential }\end{array}$ & Essential & \\
\hline \multirow{3}{*}{ Age } & $<40$ yrs & $17(94.4)$ & $17(85)$ & \multirow[t]{3}{*}{$2.811(0.211,37.393) \times$} \\
\hline & $>40$ yrs & $1(5.6)$ & $3(15)$ & \\
\hline & Total & $18(100)$ & $20(100)$ & \\
\hline \multirow{3}{*}{ Gender } & Male & $4(20)$ & $7(38.9)$ & \multirow{3}{*}{$2.568(0.582,11.333) \times$} \\
\hline & Female & $16(80)$ & $11(28.9)$ & \\
\hline & Total & $20(100)$ & $18(100)$ & \\
\hline \multirow{3}{*}{ Employment } & Employed & $6(33.3)$ & $6(30)$ & \multirow[t]{3}{*}{$0.948(0.225,3.998) \times$} \\
\hline & Unemployed & $12(66.7)$ & $14(70)$ & \\
\hline & Total & $18(100)$ & $20(100)$ & \\
\hline \multirow{3}{*}{$\begin{array}{l}\text { Monthly } \\
\text { Income }\end{array}$} & $<10000$ & $16(88.9)$ & $17(85)$ & \multirow[t]{3}{*}{$1.148(0.129,10.205) \times$} \\
\hline & $>10000$ & $2(11.1)$ & $3(15)$ & \\
\hline & Total & $18(100)$ & $20(100)$ & \\
\hline
\end{tabular}

$\times p>0.05$, statistically not significant

Table 3 depicts that doctors have a 1.148 times more tendency of prescribing essential drug to a patient who have monthly income more than 10000 compared to monthly income $<10000$ and incase of age group $>40$ year 2.811 times more compared to $<40$ years, employed patient 0.948 times and to female patients 2.568 times more than male patients.

\section{Figure 2: Most common Anxiolytics prescribed}

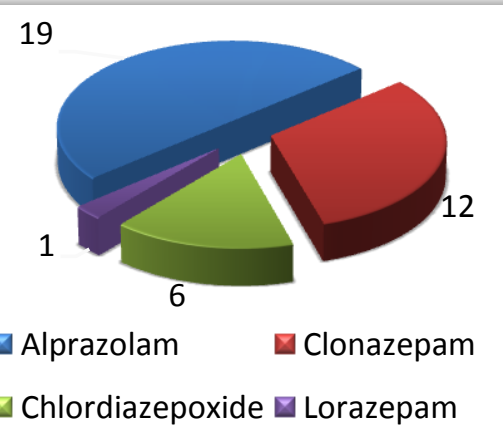


Figure 2 depicts the most common anxiolytics prescribed were alprazolam 19 (50) and clonazepam 12 (31.6) followed by chlordiazepoxide 6(15.8) and lorazepam 1(2.6).

Table 4: Cross tabulation between Socio demographic factors and Anxiolytic drugs prescribed

\begin{tabular}{|c|c|c|c|c|c|}
\hline \multirow{2}{*}{\multicolumn{2}{|c|}{$\begin{array}{l}\text { Socio demographic } \\
\text { factors }\end{array}$}} & \multicolumn{4}{|c|}{ Drugs Prescribed } \\
\hline & & \multirow{2}{*}{\begin{tabular}{|l} 
Alprazolam \\
$15(78.9)$
\end{tabular}} & \multirow{2}{*}{$\begin{array}{l}\text { Clonazepam } \\
12(100)\end{array}$} & \multirow{2}{*}{$\begin{array}{l}\text { Chlordiazepoxide } \\
6(100)\end{array}$} & \multirow{2}{*}{$\begin{array}{l}\text { Lorazepam } \\
1(100)\end{array}$} \\
\hline \multirow{4}{*}{ Age } & $<40$ yrs & & & & \\
\hline & $>40$ yrs & $4(21.1)$ & $0(0)$ & $0(0)$ & $0(0)$ \\
\hline & Total & $19(100)$ & $12(100)$ & $6(100)$ & $1(100)$ \\
\hline & P Value & $0.0001+$ & - & - & - \\
\hline \multirow{4}{*}{ Gender } & Male & $4(21.1)$ & $3(25)$ & $3(50)$ & $1(100)$ \\
\hline & Female & 15(78.9) & $9(75)$ & $3(50)$ & $0(0)$ \\
\hline & Total & 19(100) & $12(100)$ & $6(100)$ & $1(100)$ \\
\hline & P Value & $0.0001 \dagger$ & $0.0004 \dagger$ & $1^{x}$ & - \\
\hline \multirow{4}{*}{ Employment } & Employed & $7(36.8)$ & $3(25)$ & $2(33.3)$ & $0(0)$ \\
\hline & $\begin{array}{l}\text { Un } \\
\text { employed }\end{array}$ & $12(63.2)$ & $9(75)$ & $4(66.7)$ & $1(100)$ \\
\hline & Total & $18(100)$ & $12(100)$ & $6(100)$ & $1(100)$ \\
\hline & P Value & $0.09^{x}$ & $0.0004 \dagger$ & $0.221^{x}$ & - \\
\hline \multirow[t]{4}{*}{$\begin{array}{l}\text { Monthly } \\
\text { Income }\end{array}$} & $\begin{array}{l}<10000 \\
\text { /month }\end{array}$ & $14(73.7)$ & $12(100)$ & $6(100)$ & $1(100)$ \\
\hline & $\begin{array}{l}>10000 \\
\text { /month }\end{array}$ & $5(26.3)$ & $0(0)$ & $0(0)$ & $0(0)$ \\
\hline & Total & $19(100)$ & $12(100)$ & $6(100)$ & $1(100)$ \\
\hline & P Value & $0.0001+$ & - & - & - \\
\hline
\end{tabular}

$+p<0.01$, statistically significant

$\times p>0.05$, statistically not significant

- P value cannot calculate

Table 4 reveals that if the age of the patient is $<40$ years $78.9 \%$ of the patients used alprazolam, if the gender of the patient is female $78.9 \%$ of the patients used alprazolam and if the monthly income of the patient is $<10000 \mathrm{Rs} /$ month $73.3 \%$ of the patients used Alprazolam which was found to be highly statistically significant in all the cases $(P=0.0001)$.

\section{Discussion}

\section{Drug Utilization Research}

Drug utilization research is defined as research on marketing, distribution, prescription and use of drugs in a society with a special emphasis on the resulting medical, social and economic consequences and has the principle aim of facilitating the essential and rationale use of the drugs. Every patient always wants a good prescription, well documented, with an optimal dose and drugs with acceptable and as few side effects as possible at an affordable price, with correct information. Drug utilization research provides a baseline reference point about the effect of various interventions on prescribing about the drugs $^{10}$. Drug utilization studies in Psychiatric disorders are few in number in Nepal. We could lay our hands only on one study done in 2001 by P. Ravishankar and S. Roy in outpatient department ${ }^{7}$. Our study was done in an impatient setting because it is easy to follow up the patients. Psychiatric cases with anxiety that were seriously ill and require inpatient admission were taken into consideration.

\section{Psychiatric diseases}

Out of 240 cases who were admitted to the psychiatric inpatient ward from October 2009 to March 2010, Schizophrenia cases were predominant $36.3 \%$ out of which $65.5 \%$ were males and $34.5 \%$ were females. This is followed by Other Psychiatric disorders like substance abuse, behavioral disturbances, suicidal tendencies and mental retardation $20 \%$, in which $60.4 \%$ patients were male and $29.6 \%$ were females. This is followed by Depression $15.8 \%$, in which $55.3 \%$ of the patients were females and $44.7 \%$ were male patients and anxiety $15.8 \%$. In this disease $71.1 \%$ of the patients were females and males were only $28.9 \%$. Bipolar disorders $8.3 \%$ and Mania $3.8 \%$ were the lowest. Our findings are different from a similar study done in Nepal in which it was shown that the prevalence of mental illness were estimated about $25 \%$ of the total population of Nepal among which $1-2 \%$ cases were Psychosis, Neurosis 10\%, Depression 4-6\%, Mental retardation 3-5\%, Alcohol abuse disorder $3-5 \%$, Narcotic and other substance use disorders $0.5 \%{ }^{11}$. In another study done in 2000 in Jiri, Nepal showed that out of 653 patients $11.08 \%$ had somatization disorder, Generalized anxiety disorder 3.5\%, Depression 3.1\%, Mania $3.6 \%$, Schizophrenia $1.4 \%$ and Antisocial personality disorder $0.2 \%{ }^{12}$.

\section{Socio-Demographic Details and Anxiety}

Out of 38 cases of anxiety, $71.1 \%$ of the patients were females and only $28.9 \%$ were males. This finding is similar to a study done by Lader $\mathrm{MH}$ et al in Australia which also showed that psychiatric disorder is more common in females ${ }^{13}$.

Maximum cases of anxiety were below 40 years of age $89.5 \%$ and only $11.5 \%$ were above 40 years of age, which is also similar to a study done by Raut $P$ in South India, which revealed that psychiatric illness occurs more in patients below 40 years of age ${ }^{14}$. A study done by Cheng Shannon J et al, showed significant increase in antipsychotics prescribing for youths, mainly because of growing use of second generation agents for non psychiatric illness ${ }^{15}$.

As far as religion is concerned, anxiety cases were more common in Hindus $97.4 \%$, followed by Christian $2.6 \%$. Among the ethnic groups, Brahmins $36.8 \%$, Chettri $31.6 \%$ were the most prominent anxiety cases followed by Dalit 23.7\%, Newar $5.3 \%$ and others $2.6 \%$. Anxiety was more commonly seen in unemployed population $68.4 \%$. As far as the monthly income is concerned, majority of the cases earned less than Rs 10000 NPR/month (86.8\%).This finding is similar to a study done in Sweden in 2006, in which it was concluded that psychotropic drug utilization was higher among individuals with low income and unmarried population ${ }^{16}$.

Anxiety was most common in housewives (39.5\%), students (21.1\%), followed by teachers (15.8\%). Qualitative research done in housewives with the personal interview tool revealed that this is due to their husbands being in foreign countries for employment, or them deserting their family in 
the village to migrate to bigger cities of Nepal, India or foreign countries.

\section{Pharmacotherapy of Anxiety}

As far as the drug utilization is concerned $50 \%$ of the patients received drug monotherapy alone which were equal to that of drug therapy and psychotherapy. None of the cases were treated by psychotherapy alone.

As far as the Trade and Generic is concerned, $78.9 \%$ of the anxiolytics were prescribed by Trade name where only $21.1 \%$ were prescribed by Generic name. Our finding is similar to a study done by Ravishankar P.R et al in 2001 on psychotropic drugs were it was found that $71.3 \%$ of the drugs were prescribed by Trade names ${ }^{7}$.

The use of Essential drug list was almost $52.6 \%$ as compared to nonessential drug list $47.4 \%$. In another study it showed that $29.48 \%$ of the drugs prescribed were from essential drug list of Nepal ${ }^{7}$. According to the essential drug list of Nepal, among the anxiolytic drugs only Alprazolam and Chlordiazepoxide are included ${ }^{17}$.

In the type of treatment given for anxiety, anxiolytics were given in $81.6 \%$ of the cases, whereas a combination of anxiolytics and antidepressants like Fluoxetine (Selective serotonin reuptake inhibitors) were given in $19.4 \%$ of the cases. Among all the cases of anxiety Benzodiazepine group of drugs were used. In none of the cases of anxiety other group of drugs like $\mathrm{H} 1$ antihistaminics, $\beta$ blockers like propranol or Azapirones like Buspirone were used. Our finding is similar to the other studies which revealed that in Benzodiazepines were the commonest psychotropic drugs prescribed $^{18}$.

Among the anxiolytics the commonest drug was Alprazolam $50 \%$, followed by Clonazepam $31.6 \%$, Chlordiazepoxide $15.8 \%$ and Lorazepam $2.6 \%$, suggesting a trend towards the use of shorter acting Benzodiazepines, as it is seen that continuous and prolonged use of longer acting Benzodiazepines has resulted in dependence and may have withdrawal symptoms when the dosage of these drugs are reduced or treatment is stopped ${ }^{19}$.

Antidepressants and Benzodiazepines are the most commonly prescribed psychotropic drugs. It is difficult to know whether these drugs are being inappropriately prescribed. Published evidence merely tells us that antidepressants are effective in moderate and severe depressive illness ${ }^{20}$. Benzodiazepines are extremely effective in promoting sleep and relieving anxiety in short term $^{21}$.

\section{Conclusion}

Utilization patterns of drugs for Anxiolytics were according to treatment guidelines i.e Alprazolam, suggesting a trend towards the use of shorter acting Benzodiazepines as it is seen that continuous and prolonged use of longer acting Benzodiazepines has resulted in dependence and may have withdrawal symptoms when the dosage of these drugs is reduced or treatment is stopped.

\section{Acknowledgments}

The authors are also thankful to Dr. B. M. Nagpal, Dean and CEO, MCOMS, Nepal, Dr S. M. Banerjee, Orthopaedic surgeon, Kalyani, West Bengal, India, Dr Ramesh K, Professor, Department of Psychiatry, MCOMS, Pokhara, Nepal, and the patients who participated in the study. We extend our sincere and deepest gratitude to $\mathrm{Dr}$ Akhilesh Chandra Jauhari, Professor, Department of Pharmacology, Manipal College of Medical sciences, Nepal for all suggestions and cooperation in carrying out this study.

\section{Authors contributions}

IB designed the study, interpreted the data, drafted the manuscript, and revised it. BR envisages the study with IB, acquired the data, conducted the data analysis, interpreted the data, and revised the manuscript. KSS revised the manuscript; BS participated in statistical analysis, interpreted the data, and revised the manuscript. SA and IB2 interpreted the data and critically revised the manuscript. All authors approved the final manuscript.

\section{References}

1. Wittchen HU. Generalized anxiety disorder: prevalence, burden, and cost to society. Depress Anxiety 2002; 16(4):162-71.

2. Dukes MNG, ed. Drug Utilization Studies: Methods and Uses. Copenhagen, WHO Regional Office for Europe, 1993 (WHO Regional Publications European Series No. 45)

3. Wittchen HU, Hoyer J. Generalized anxiety disorder: nature and course. J Clin Psychiatry 2001; 62 (11):15-9.

4. Davidson JR, Feltner DE, Dugar A. Management of generalized anxiety disorder in primary care: identifying the challenges and unmet needs. Prim Care Companion J Clin Psychiatry 2010; 12(2).

5. Ustun TB, Sartorius N. Mental Illness in General Health Care: An International Study. New York, NY: John Wiley \& Sons Inc; 1995, pp 323-335.

6. Alonso J, Angermeyer MC, Bernert S, Bruffaerts R, Brugha TS, Bryson $\mathrm{H}$, et al. Prevalence of mental disorders in Europe: results from the EuropeanStudy of the Epidemiology of Mental Disorders (ESEMeD) project. Acta Psychiatr Scand Suppl 2004; (420):21-7.

7. Shankar PR, Roy S. Patterns of prescription and drug use in psychiatry outpatient department in a teaching hospital in Western Nepal. The Internet Journal of Pharmacology 2002; 1(2).

8. Sathian B, Sreedharan J, Baboo NS, Sharan K, Abhilash E S, Rajesh E. Relevance of Sample Size Determination in Medical Research. Nepal Journal of Epidemiology 2010; 1(1): 4-10.

9. Nervous System. ATC/DDD Index. WHO collaborating centre for drug statistics methodology. [online] 2011 [cited 2011 July 19]. Available from: URL:http://www.whocc.no/ atc_ddd_index/?code=N

10. Shankar PR. Drug utilization and rational use of medicines. Drug information Bulletin 2007; 5(3):6-8.

11. Lamichhane N. Mental Health in Nepal. Virtual Doctor. [Online] 21 Aug 2008 [cited 2011 August 1]. Available 
from:URL:http://www.pokharacity.com/virtual-

doctor. php?subaction=showfull\&id=1219337345\& archive $=1$ 245362037\&start_from $=$ \&ucat $=74 \&$

12. Tausig M,Subedi S,Subedi J, Ross J, Broughton L C, et al. Mental illness in Jiri Nepal. The Jirel issue 2000:105-15.

13. Mant A, Lansbury G, Bridges-Webb C. Trends in psychotropic drug prescribing in Australia. Med J Aust1987; 146(4):208-10.

14. Raut P. Drug utilization pattern of Psychotropic drugs in Kasturba hospital [dissertation]. Kasturba Medical College: Manipal Univ., 2006.

15. Chakos M, Lieberman J, Hoffman E, Bradford D, Sheitman B. Effectiveness of second-generation antipsychotics in patients with treatment-resistant schizophrenia: a review and meta-analysis of randomized trials. Am J Psychiatry 2001; 158(4):518-26.

16. Lesen E, Anderrson K, PetzoidM, Carlsten A. Socioeconomic determinants of Psychotropic drug utilization among elderly: a national population based cross sectional study. BMC Public Health 2010; 10:118.

17. Bhattarai DD, Shrestha DA, Dixit H, AcharyaLI, KafleKK, Prasad RR, Thapa BB. National List of Essential Drugs. Nepalese National Formulary. 1sted. Kathmandu:Kanchan Printing Press,1997,pp 353.

18. Jacobson GA, Friesen WT, Peterson GM, Rumble RH, Polack AE.Psychoactive drug prescribing in the Tasmanian community.Med J Aust.1992;157(1):20-4.

19. Tyrer PJ. Benzodiazepine dependence and propranolol. Pharmaceutical Journal 1980; 225 : 158-60.

20. Morris JB, Beck AT.The efficacy of antidepressant drugs. A review of research (1958-1972).Arch Gen Psychiatry 197; 30(5):667-74.

21. Lader $\mathrm{MH}$, Bond AJ, James DC. Clinical comparison of anxiolytic drug therapy. Psychol Med 1974; 4(4):381-7.

\begin{tabular}{|c|c|}
\hline \multicolumn{2}{|c|}{ Article Information } \\
\hline \multicolumn{2}{|c|}{ Article history } \\
\hline Received & 10 August 2011 \\
\hline Received in revised form & 25 August 2011 \\
\hline Accepted & 1 September 2011 \\
\hline
\end{tabular}

